\title{
Priority public health interventions and research agendas in post-earthquake Nepal
}

\author{
Pramod R. Regmi ${ }^{1}$, Nirmal Aryal ${ }^{2}$, Puspa Raj Pant ${ }^{3}$, Edwin van Teijlingen ${ }^{4}$, Padam Simkhada $^{5}$,
} Bhimsen Devkota ${ }^{6}$

\begin{abstract}
${ }^{1}$ Post Doctoral Research Fellow, Faculty of Health and Social Sciences, Bournemouth University, UK; Visiting Research Fellow, Chitwan Medical College, Tribhuvan University, Nepal. ${ }^{2} \mathrm{PhD}$ Student, Department of Medicine, University of Otago, Wellington, New Zealand. ${ }^{3}$ Research Associate, Centre for Child and Adolescent Health, University of the West of England, UK. ${ }^{4}$ Professor of Reproductive Health, Centre for Midwifery, Maternal and Perinatal Health, Bournemouth University, UK; Visiting Professor, Manmohan Memorial Institute of Health Sciences, Tribhuvan University, Nepal; Visiting Professor, Nobel College, Pokhara University, Nepal. ${ }^{5}$ Professor of International Public Health, Liverpool John Moores University, UK; Visiting Professor, Manmohan Memorial Institute of Health Sciences, Tribhuvan University, Nepal; Visiting Professor, Nobel College, Pokhara University, Nepal. ${ }^{6}$ Professor of Health Education, Tribhuvan University, Nepal.
\end{abstract}

\section{Abstract}

The occurrence of natural disasters including earthquake is becoming more frequent phenomena worldwide. All these disasters trigger huge damages to infrastructure, economies as well as population health. Nepal's earthquake in 2015 has multiple effects on population health and health services delivery. Many public health facilities, mostly health posts or sub-healthposts, were damaged or completely destroyed. Priority health services such as immunization and antenatal care were also seriously affected. The earthquake has prompted the need for a disaster-related population-health-research agenda as well as renewed disaster strategy in post-earthquake Nepal. Meanwhile, it also unveiled the gap in knowledge and practice regarding earthquake resilience in Nepal. There is an opportunity for school-based and community-based interventions in both disaster preparedness and resilience. Nepal can build on experiences from other countries as well as from its own. We have discussed possible impacts of the Nepal earthquake on population health and health system infrastructures. We have also suggested possible public health interventions bestowing active awareness among the population and a research agenda in this regard. We strongly urge for the translation of the National Health Policy (2014) into action, as it prioritizes the need of an earthquake resistant infrastructure as well as the implementation of a disaster response plan.

Keywords: Natural disasters, Earthquake, Public health interventions, Research agenda, Nepal.

\section{Introduction}

The occurrence of natural disasters such as floods, mudslides, tsunamis, and earthquakes are becoming more frequent phenomena triggering huge damages to infrastructures, economies as well as to population health. Naghii ${ }^{1}$ reported that on average two earthquakes strike every minute, equivalent to more than one million earthquakes globally per year. There is no doubt that we have achieved an incredible scientific progress in our understanding of earthquakes, but achieving a high standard of health and safety to protect against the effects of earthquakes is still a major global challenge.

On $25^{\text {th }}$ April 2015, a 7.8 magnitude earthquake with several major aftershocks struck Nepal killing approximately 9,000 people and directly affecting onethird of its 26 million people. ${ }^{2}$ Stress accumulated between the Eurasian and the Indian Plates often cause frequent earthquakes ${ }^{3}$ and there have been several major earthquakes in Nepal over the past century in 1934, 1980, 1988 and 2011.4

The recent earthquakes in Nepal have had a severe impact in 31 out of the countries' 75 districts, of which 14 were declared 'crisis-hit', and resulted enormous human and

\section{Practice Points}

- Achieving a high standard of health and safety to protect against the effects of natural disasters is still a major global challenge.

- We know little about people's coping with and resilience to natural disasters in Nepal.

- Health service provisions after disasters need a multi-disciplinary approach and professionals from a variety of specialities.

- Schools are the most appropriate place where children and adolescents can be easily accessed en masse.

- Nepal urgently needs a proper research agenda on disaster-related health issues.

economic loss. ${ }^{5}$ It has damaged public buildings, heritage sites, educational institutions, health facilities, and road networks. For example, the earthquake completely destroyed over 488,700 public buildings and damaged $267,477 .{ }^{2}$ This has also affected tourism in Nepal which accounts for $3.9 \%$ of the national gross

Correspondence: Dr. Pramod R. Regmi, Post Doctoral Research Fellow, Faculty of Health and Social Sciences, Bournemouth University, England, UK. Email: pregmi@bournemouth.ac.uk. 
domestic product (GDP) and $3.2 \%$ of total employment. ${ }^{6}$ The National Planning Commission estimated a loss of US\$ 7 billion (706 billion Nepalese Rupees $)^{5}$ which is equivalent to $86 \%$ of the budget allocated for the fiscal year $2015 / 2016 .^{7}$ Moreover, it has been estimated that this earthquake will push an additional 2.5 to $3.5 \%$ of the Nepalese population into poverty by $2016 .{ }^{5}$ Similarly, a rapid assessment carried out after the earthquake also suggests that earthquake has instigated individuals in the crisis hit districts to consider migration for recovery. ${ }^{8}$

Earthquakes in low-income countries usually disproportionately affect more disadvantaged communities, as is the case in Nepal where the worst affected districts are remote and poor areas with already compromised health care, transportation, and infrastructure. 9 The earthquakes have an impact on both population health and health systems. Khanal and colleagues ${ }^{10}$ speculated that gains achieved in the maternal and child health indicators in Nepal will be hard to maintain after the earthquake.

There is abundant literature on the impact of natural disasters. Particularly, the impacts on mental health during and post-natural disasters including earthquakes have been well discussed. ${ }^{11}$ However, there is limited literature around consequences of natural disasters such as flood, and earthquake on public health and the health system. This paper, therefore, addresses the impact of earthquake on the population's health and health infrastructures in Nepal and recommends potential interventions and research priorities in the postearthquake era.

\section{Impact of earthquakes on health}

Natural disasters including earthquake can have serious social and health consequences ${ }^{12,13}$ and these consequences can be very complex. The immediate effect is on mortality and morbidity from collapsed buildings or structures. The number of casualties from natural disasters, however, depends on the magnitude, its proximity to densely populated areas, and the degree of disaster preparedness. ${ }^{1}$ In most cases, deaths resulting from major earthquakes are instantaneous due to severe crushing injuries to the head or chest, external or internal hemorrhage or delayed, the latter occur in the immediate aftermath due to dust inhalation of collapsed building, dehydration, hypothermia, hyperthermia, crush syndrome, wound infections, or postoperative sepsis. ${ }^{14}$ Older people ( $>60$ years) and children between the ages five to nine in particular are at an increased risk of injury and/or death. ${ }^{15,16} \mathrm{~A}$ further risk is outbreak of communicable diseases after the earthquake due to poor sanitation facilities and crowded sheltering. ${ }^{12}$ Fortunately, there were no significant outbreaks of communicable diseases and infections after the 2015 earthquakes in Nepal. However, Basnyat and colleagues $^{17}$ argued that there may be a risk of epidemics of infectious diseases such as cholera, hepatitis E, typhoid, and typhus which is already endemic in Nepal, hence continued disease surveillance in post-earthquake Nepal is necessary.
The consequences of earthquake on population health are not limited to physical injuries. They also include an increase in adverse consequences of chronic illness, for example, the mortality rate from heart attacks increased by $50 \%$ in the first three days of 1981 Athens earthquake. ${ }^{1}$ In the aftermath of 1995 Japan earthquake, glycemic control was impaired in diabetic patients. ${ }^{18}$ Likewise, systolic blood pressure and diastolic blood pressure increased by $15-16 \mathrm{mmHg}$ and $6-10 \mathrm{mmHg}$ respectively for first two weeks in elderly patients, suggesting a link between chronic, life-threatening stress and the worsening of metabolic control. Anecdotal records also suggest that people with conditions, whose risk factors include stress and requiring ongoing health care, are severely impacted by disasters. $^{19}$

Several studies ${ }^{20-24}$ report that natural disasters have a significant mental health impact, particularly on children and adolescents. There is evidence that elderly and women are also vulnerable to poor mental health following an earthquake. For example, a survey of survivors of the 2008 Sichuan earthquake showed that elderly survivors were more likely to develop posttraumatic stress disorder (PTSD) and general psychiatric morbidity. ${ }^{25}$ Similarly, Chinese women were approximately twice as likely to develop PTSD and $60 \%$ were more likely to report anxiety and depression when experiencing a traumatic earthquake. ${ }^{26}$ Mild mental distress usually affects $20-40 \%$ of the people in post-natural disaster areas ${ }^{27}$ and the prevalence of PTSD in victims of earthquake ranges from $10 \%$ to $87 \%$. $^{22}$ There are also reports that large-scale community trauma can result in: (a) a significant increase in psychological problems in the short-term; and (b) can have significant negative physical and mental health consequences for years after the disaster. ${ }^{28-30}$

This earthquake may impact on the nutritional status in affected areas, especially in children, pregnant and lactating women who constitute the primary vulnerable groups. Recent post-earthquake assessments in Nepal found poor food consumption in the affected districts compared to pre-earthquake assessment data. ${ }^{31}$ Although there has been a reduction in under nutrition in Nepal, disparity between socio-economic groups, urban and rural areas, however, is growing. Anemia is high at $46 \%$ among children aged 6-59 months and the prevalence of stunting remains high at $40 \%$ suggesting this is another priority area in postearthquake Nepal.

\section{Impact on the health system and infrastructures}

Nepal's earthquakes cause major setbacks in the health service, further inhibiting access to already poor rural health care and reducing its quality. The health infrastructure in the 14 severely affected districts was severely damaged, as 389 public health facilities, mostly sub/health posts were completely destroyed and 403 partly damaged including ten referral hospitals in the capital Kathmandu. ${ }^{2}$ About $32 \%$ of facilities providing specialized maternal and neonatal services were also 
destroyed. Such destruction has a huge impact on health care delivery in the earthquake-affected areas because $\mathrm{sub} /$ health posts are the first point of access for basic health services and a significant proportion of Nepali population use public health services. For example, during the fiscal year 2013/14, more than two-thirds of the population $(70 \%)$ used these public health services. ${ }^{33}$ This earthquake has also seriously affected priority health services such as immunization, family planning, antenatal care, safe delivery services, services to Tuberculosis (TB) patients and people living with Human Immunodeficiency Virus (HIV). The United Nations Population Fund (UNFPA) estimated 1.4 million women of reproductive age were affected, including an estimated 93,000 pregnant women (and up to 10,000 delivering each month). ${ }^{34}$ The impact on health infrastructure destruction could further worsen the up-take of health facility deliveries which is already low in Nepal (35\%). ${ }^{35}$ Some have questioned whether the health infrastructures damage can be repaired with the available resources; hence they stress the need for financial supports from Nepal's development partners. ${ }^{3}$

The impact of 2015 earthquakes corroborated that Nepalese health institutions are ill prepared to cope with the earthquakes. Most of the hospitals and health facilities, for example, had little or no strategy on patient evacuation, continuation of medical support, or handling large number of injured people. ${ }^{36}$ The mass media often reported that during the April 2015 earthquake, patients, including those at intensive care units, were left stranded on the floor without health care staff attending for hours in some of the major hospitals. ${ }^{37,38}$ However, despite the damage in infrastructure and short supply of drugs and equipment, we observed that Nepal's health institutions along with international medical teams worked to treat the casualties round the clock.

\section{Population health responses in post- earthquake areas}

There are few evidence-based interventions that could be implemented in post-earthquake or other postdisaster settings. Our narrative review suggests that interventions in previous disaster settings have mainly focused on educational institutions, ${ }^{39}$ community level, ${ }^{40,41}$ and primary health care centers. ${ }^{23}$

A systematic review showed that schools are key providers of mental health services for young people in post-disaster settings and indicated that teachers may be efficacious at administering general, school-based, mental health interventions. ${ }^{39}$ Schools can offer a feasible setting to implement large-scale post-disaster interventions. ${ }^{42}$ Sri Lanka's Happy/Sad Letter Box to minimize trauma in children resulting from the Indian Ocean tsunami is an example of a successful schoolbased intervention. ${ }^{43}$ Schools are one of the appropriate places where children and adolescents can be easily accessed en masse. Some organizations have already initiated school-based interventions in Nepal such as incorporating disaster-related contents in the curriculum, practising 'duck, cover and hold drills'; their experiences can help to develop further schoolbased strategy to cope disasters effectively. ${ }^{44}$

Similarly, a controlled intervention administered through primary health care in Iran improved disaster awareness and readiness at the community level. ${ }^{41}$ In Nepal, female community health volunteers (FCHVs) are the backbone of primary health care programs, ${ }^{45}$ thus, their involvement in the disaster awareness and preparedness activities will be much beneficial, particularly in rural areas. Community-based education interventions for disaster awareness and preparedness can be implemented by FCHVs targeting the general population.

There are various models for effective health service provisions in post-disasters and humanitarian settings. The dominant model for psychological intervention has been the medical model. ${ }^{23,46}$ These models focus on clinic-based services by highly trained professionals. An approach based in Primary Health Care with preparedness and intervention activities is also reported to have a good efficiency. ${ }^{41}$ Similarly, Psychological First Aid (PFA) is an 'old' approach but it lacks adequate scientific evidence of efficiency. ${ }^{47}$ Kelley and Greenbaum, ${ }^{48}$ for example, have presented a model of using local organizations as leverage for effective delivery of sexual and reproductive health care when responding to a disaster. Likewise, a stepped-care model provides graduated service response starting with a less intensive intervention. ${ }^{49}$ Another helpful strategy to cope with the mental illness in post-natural disaster settings is 'mindfulness', but further research is still necessary. ${ }^{50}$

It is accepted that health service provisions after a disaster need a multi-disciplinary approach including professionals from a variety of specialties. ${ }^{51}$ While some provide family therapy, others may include individual counseling, or psycho-pharmacological treatments. These models of health service provision may be more effective in reducing symptoms, impairment, and improving the quality of life of individuals, especially around mental health conditions. ${ }^{49}$ Beside this, Narrative Exposure Therapy (NET) has been used in mental health services after disasters. ${ }^{52}$ While implementing such interventions, local peculiarities have to be given ample consideration to decide on the provision of health services in post-disaster settings. It is also very important to understand the different stages in post-disasters settings while designing an intervention. The following five stages were developed by the American Red Cross: ${ }^{53}$

1. Initial impact phase-characterized by increased anxiety and fears.

2. Heroic phase-survivors help each other to deal with the catastrophe.

3. Honeymoon phase-experiences of joy and happiness at having survived and the feeling of being important

4. Disillusionment phase-increased resentment and frustration at officials and agencies for 
failing to provide assistance in a more timely fashion.

5. Reconstruction phase-characterized by thoughts and plans for reconstruction and acceptance of the need to assume responsibility for personal problems.

\section{Developing health research agenda for post-earthquake Nepal}

A rapid database search using keywords 'Nepal or Kathmandu', and 'Earthquakes' (conducted in August 2015 ) resulted in 22,022 items. Surprisingly, there were 219 articles published in academic journals, indicating the growing global interest in Nepal's recent earthquakes. Based on this review and our post-earthquake observations, we summarized key messages important for the development of the research and intervention agenda in post-earthquake era. We suggest that Nepal should develop its disaster- related national health research agenda covering issues such as:

1. Mental health, psychosocial needs, posttraumatic stress disorders;

2. Neonatal and child health; nutritional intake, immunization coverage;

3. Cardio-pulmonary conditions;

4. Outbreak of communicable diseases;

5. Injuries/management of trauma;

6. Sexual and reproductive health: utilization of antenatal care, delivery care, post-natal care, availability of family planning, sexual abuses in make-shift shelters;

7. TB and HIV (service provision and adherence);

8. Disaster response plan and existing coping capacity and resilience among health care institutions.

\section{Final thoughts}

Damaged health infrastructures in affected areas have not only impeded provision of basic and emergency health care services but also halted the continuous progress gained in maternal and child health and other important population health indicators. Thus, we suggest that Nepal should continue to provide health services through its transitional health centers until permanent infrastructures are fully rebuilt/restored and service provision resumed. Obviously this is very challenging and may take several years due to Nepal's difficult geographical settings. Moreover, we suggest enhancing the capabilities of Nepal's health care facilities to tackle to any future disasters. Similarly, mass media, volunteers and community-based organizations could have played an important role in disseminating health promotion and safety messages. Lesson learned from these practices can be implemented in other humanitarian settings. Rapid assessments and multiple consultations engaging stakeholders in the affected areas would help to make an as accurate as possible assessment of the local situation.

This paper suggests that school-based interventions and community-based interventions, particularly on disaster preparedness or mental health issues would be the most South East Asia Journal of Public Health 2015;5(2):7-12 efficient strategies as a starting point. School-based interventions may involve teachers, students and parents whereas FCHVs and NGOs (Non-Governmental Organizations) can be involved in community-based interventions. Experiences gained from the previous school-based disaster risk reduction programs and success stories of FCHV mobilizations should be meticulously appraised. The local community knows its own vulnerabilities, local hazards and capacity best, thus, they can mobilize existing community resources to prepare for and mitigate the effects of disasters most effectively. Indeed, community empowerment and participation are imperative for disaster resilience. Coordination and support from locally based organizations would ease the implementation of such activities.

We also suggest few possible broader health research agendas for post-earthquake Nepal. These research agendas should be developed through multiple consultations and engagement of local stakeholders and experts as required. Development of a research agenda is a scientific process and is not new to Nepal. The Nepal Health Research Council (NHRC) ${ }^{54}$ and the National Centre for AIDS and STI Control (NCASC) ${ }^{55}$ have an experience of developing national research agenda in the past and there are literature available around research agenda priority setting. ${ }^{56}$ Lessons from elsewhere can also be utilized while developing such agenda. ${ }^{57,58}$ Ethics in health research and interventions; particularly in humanitarian setting is another important areas. Hunt et $\mathrm{al}^{59}$ have recently proposed a set of important research questions for humanitarian health ethics. Given the current situation, it will be obvious that higher education academics, research agencies, government, NGOs and INGOs need to pay much attention to undertake research in earthquake settings. Thus, developing research agendas will help in reducing duplication and prioritize the highly needed research.

The recently implemented National Health Policy (2014) has underscored the need of earthquake resistant health buildings; retrofitting the existing ones and implementing disaster response plan. ${ }^{60}$ This is indeed an opportune time for Nepalese health system to translate these policies into action. We also have a notion that health service motives have to be shifted to the management of long-term disabilities and preparation for similar future events. ${ }^{61}$ Acquired learning during this earthquake has to be utilized to strengthen evidencebased public health practices in the country and to fill the loopholes in the post-disaster recovery strategies. ${ }^{4}$ We suggest that community disaster reduction programs must be integrated into routine public health service delivery in order to ensure its sustainability.

\section{References}

1. Naghii M. Public health impact and medical consequences of earthquakes. Pan Am J Public Health 2005; 18(3): 216-21.

2. Ministry of Health and Population. Health Sector Response: Earthquake 2015. Daily Situation Update Report. Kathmandu: Health Emergency Operation Centre. 2015 http://heoc.mohp.gov.np/ 
index.php/2-uncategorised/18-graphs-charts (accessed Dec 2015)

3. Binns C, Low W. Nepal Disaster: A Public Health Response Needed. Asia Pac J Public Health 2015; 27(5): 484-5.

4. Simkhada P, van Teijlingen E, Pant P, Sathian B, Tuladhar G. Public Health, Prevention and Health Promotion in Post-Earthquake Nepal. Nepal J Epidemiol 2015; 5(2); 462-4.

5. National Planning Commission. Nepal Earthquake 2015, Post-disaster Needs Assessment 2015. Kathmandu: National Planning Commission, 2015.

6. World Travel and Tourism Council. Travel \& Tourism Economic Impact 2014 Nepal. London: World Travel and Tourism Council, 2014.

7. Ministry of Finance. Budget Plan for 2015/16 Fiscal Year. Kathmandu: Ministry of Finance, 2015.

8. Sijapati B, Baniya J, Bhandari A, Bhattarai A, Kharel S, Limbu A, et al. Migration and Resilience: Experience from Nepal's 2015 Earthquake. Kathmandu: Centre for the study of Labour and Mobility, 2015.

9. Nour N. Maternal Health Considerations during Disaster Relief. Rev Obstet Gynecol 2011;4 (1):22-7.

10. Khanal V, Khanal P, Lee A. Sustaining progress in maternal and child health in Nepal. Lancet 2015; 385(9987): 2573.

11. Petal M. Earthquake Casualties Research and Public Education. In Spence R, Imily S, Charles $S$ (Eds) Human Casualties in Earthquake. Netherlands: Springer, 2011.

12. Watson J, Gayer M, Connolly M. Epidemics after Natural Disasters. Emerg Infect Dis 2007; 13(1):1-5.

13. Noji E. The public health consequences of disasters. Prehosp disaster med 2000;15 (4): 147 $-57$.

14. Partridge R, Proano L, Marcozzi D, Garza A, Nameth I, Brinsfield K, et al. (Eds.). Oxford American Handbook of Disaster Medicine. Oxford University Press, 2012.

15. Bödvarsdóttir Í, Elklit A, Gudmundsdottir D. Post-traumatic Stress Reactions in Children after two large Earthquakes in Iceland. Nord Psychol 2006; 58, 91-107.

16. Close R, Maguire H, Etherington G, Brewin C, Fond K, Saliba V, et al. Preparedness for a major incident: reaction of an epidemiology protocol for a health protection register in England. Environ Int 2014; 72: 75-82.

17. Basnyat B, Tabin C, Farmer P. Post-earthquake Nepal: the way forward. Lancet Glob Health 2015; 3(12): e731-e732.

18. Inui $\mathrm{A}$, Kitaoka $\mathrm{H}$, Majima $\mathrm{M}$, Takamiya $\mathrm{S}$ Uemoto M, Yonenaga C. Effect of the Kobe Earthquake on Stress and Glycemic Control in Patients With Diabetes Mellitus. Arch Intern Med 1998;158(3):274-8.

19. Regmi P, Aryal N. Public health impact of earthquakes. http://setopati.net/opinion/6346/Public- health-impact-of-earthquakes/

(accessed

November 2015)

20. Neuner F, Schauer E, Catani C, Ruf M, Elbert T. Post-tsunami stress: a study of posttraumatic stress disorder in children living in three severely affected regions in Sri Lanka. $J$ Trauma Stress 2006; 19(3): 339-47.

21. North C, Pfefferbaum B. Mental Health Response to Community Disasters A Systematic Review. JAMA 2013; 310(5):507-18.

22. Altindag A, Ozen S, Sir A. One-year follow-up study of posttraumatic stress disorder among earthquake survivors in Turkey. Compr Psychiatry 2005; 46(5): 328-33.

23. Yoder, M, Tuerk P, Axsom D. Evaluation of an Ecological Intervention Targeting Helpers in the Aftermath of Disasters. Int Perspect Vict 2015; 6 (2):134-42.

24. Xu J, Ou L. Resilience and quality of life among Wenchuan earthquake survivors: the mediating role of social support. Public Health 2014; 128 (5):430-7.

25. Jia Z, Tian W, Liu W, Cao Y, Yan J, Shun Z. Are the elderly more vulnerable to psychological impact of natural disaster? A population-based survey of adult survivors of the 2008 Sichuan earthquake. BMC Public Health 2010;10:172.

26. Zhang Z, Wang W, Shi Z, Wang L, Zhang J. Mental health problems among the survivors in the hard-hit areas of the Yushu Earthquake. PLoS One 2012;7(10): e46449.

27. World Health Organization. Mental health assistance to the populations affected by the tsunami in Asia. http://www.who.int/ mental_health/resources/tsunami/en/index 1.html (accessed November 2015)

28. Chou F, Wu H, Chou P, Su C, Tsai K, Chao S, et al. Epidemiologic psychiatric studies on postdisaster impact among Chi-Chi earthquake survivors in Yu-Chi, Taiwan. Psychiatry Clin Neurosci 2007;61(4):370-8.

29. Bromet E, Dew M. Review of psychiatric epidemiologic research on disasters. Epidemiol. Rev 1995;17(1):113-9.

30. Brewin C, Andrews B, Valentine J. Meta-analysis of risk factors for posttraumatic stress disorder in trauma-exposed adults. $J$ Consult Clin Psychol 2000;68(5):748-66.

31. The World Bank. Nepal Earthquake post disaster needs assessment : sector reports. Washington, D.C.: World Bank Group, 2015. http://documents.worldbank.org/curated/ en/2015/06/24663885/nepal-earthquake-postdisaster-needs-assessment-sector-reports (accessed September 2015)

32. The World Bank. Accelerating Progress in Reducing Maternal and Child Under nutrition in Nepal. Kathmandu: The World Bank, 2012.

33. Ministry of Health and Population. Annual Report 2013/14. Kathmandu: Department of Health Services, 2014.

34. United Nations Population Fund. Nepal Earthquake 100 Days into the Humanitarian Response. 
New York: UNFPA, 2015.

35. Ministry of Health and Population, New ERA, ICF International Inc. Nepal Demographic and Health Survey 2011. Kathmandu: Ministry of Health and Population, New ERA, and ICF International, Calverton, Maryland, 2012.

36. Kazmin A, Bhattarai B. Nepal earthquake: Rescue teams and hospitals struggle to cope. Nepal earthquake: Rescue teams and hospitals struggle to cope. http://www.ft.com/cms/s/0/924ca614ec2a-11e4-b428-00144feab7de.html\#slide0 (accessed December 2015).

37. Davey M, Tan M, Weaver M, Walker P. Nepal Earthquake 2015. http://www.theguardian.com/ world/live/2015/apr/28/nepal-earthquake-deathtoll-climbs-past-4000-with-many-more-missingrolling-report (accessed Dec 2015)

38. United Nations. Nepal Earthquake Situation Report 04-1. Kathmandu: United Nations, 2015.

39. Franklin C, Kim J, Ryan T, Kelly M, Montgomergy K. Teacher involvement in school mental health interventions: A systematic review. Child Youth Serv Rev 2012; 34(5): 973-82.

40. Kowalski K, Kalayjian A. Responding to mass emotional trauma: a mental health outreach program for Turkey earthquake victims. Safety Sci 2001; 39 (1):71-81.

41. Ardalan A, Mowafi H, Ardakani H, Abolhasanai F, Zanganeh A, Safizadeh H, et al. Effectiveness of a Primary Health Care Program on Urban and Rural Community Disaster Preparedness, Islamic Republic of Iran: A Community Intervention Trial. Disaster Med Public Health Prep 2013; 7 (5): 481-90.

42. Chemtob C, Nakashima J, Hamada R. Psychosocial intervention for post disaster trauma symptoms in elementary school children: A controlled community field study. Arch Pediatr Adolesc Med 2002; 156 (3):211-6.

43. Commers M, Morival M, Devries M. Toward best-practice post-disaster mental health promotion for children: Sri Lanka. Health Promot Int 2014;29(1):165-70.

44. Jimee G, Upadhyay B, Shrestha S. Earthquake Awareness Programs as a Key for Earthquake Preparedness and Risk Reduction: Lessons from Nepal. http://www.iitk.ac.in/nicee/wcee/article/ WCEE2012 5202.pdf (accessed Dec 2015)

45. Glenton C, Scheel I, Pradhan S, Lewin S, Hodgins S, Shrestha V. The female community health volunteer programme in Nepal: Decision makers' perceptions of volunteerism, payment and other incentives. Soc Sci Med 2010;70 (12):1920-7.

46. Miller K, Rasco L. An ecological framework for addressing the mental health needs of refugees. In K. E. Miller \& L. M. Rasco (Eds.) The mental health of refugees: Ecological approaches to healing and adaptation, Mahwah, NJ: Lawrence Erlbaum Associates, 2004:1-64.

47. Fox J, Burkle F, Bass J, Pia F, Epstein J, Markenson D. The effectiveness of psychological first aid as a disaster intervention tool: research analysis of peer-reviewed literature from 1990-2010. Disaster Med Public Health Prep 2012; 6 (3), 247-52.

48. Kelley R, Greenbaum C. Local organizations' critical role in the provision of reproductive health care during disaster response. Health Hum Rights J. 2012 . $\quad$ h t tp:// www.hhrjournal.org/2012/04/20/1ocalorganizations-critical-role-in-the-provision-ofreproductive-health-care-during-disasterresponse/ (accessed October 2015)

49. McDermott B, Cobham V. A stepped-care model of post-disaster child and adolescent mental health service provision. Eur J Psychotraumatol $2014 ; 5$.

50. Miller J. Does the evidence that mindfulnessbased interventions may assist counsellors and their clients post-earthquake stack up? Couns Psychol Q 2012; 25 (3): 339-42.

51. Jafari N, Shahsanai A, Memarzadeh M, Loghmani A. Prevention of communicable diseases after disaster: A review. $J$ Res $\mathrm{Med} S \mathrm{Sci}$ 2011: 16(7): 956-62.

52. Zang Y, Hunt N, Cox T. A randomised controlled pilot study: the effectiveness of narrative exposure therapy with adult survivors of the $\mathrm{Si}$ chuan earthquake. BMC Psychiatry 2013;13:41.

53. American Red Cross. Disaster Manual on Health Services I. New York: American Red Cross, 1992.

54. Nepal Health Research Council. National Health Research Priorities in Nepal. Kathmandu: Nepal Health Research Council, 2013.

55. National Centre for AIDS and STD Control. National HIV Research Agenda in Nepal 2013. Kathmandu: National Centre for AIDS and STD Control, 2013.

56. Viergever R, Olifson S, Ghaffar A, Terry R. A checklist for health research priority setting: nine common themes of good practice. Health Res Policy Syst 2010;8:36.

57. Lenaway D, Halverson P, Sotnikov S, Tilson H, Corso L, Millington W. Public Health Systems Research: Setting a National Agenda. Am $J$ Public Health 2006; 96 (3):410-3.

58. Acosta J, Nelson C, Beckjord E, Shelton S, Murphy E, Leuschner $\mathrm{K}$, et al. A National Agenda for Public Health Systems Research on Emergency Preparedness. Pittsburg: RAND Corporation, 2009.

59. Hunt M, Schwartz L, Pringle J, Boulanger R, Nouvet E, O'Mathuna D. A Research Agenda for Humanitarian Health Ethics. PLOS Currents Disasters 2014;Aug 12 (Edition 1). doi: 10.1371/ curents.dis.8b3c24217d80f3975618fc9d9228a14 4.

60. Ministry of Health and Population. National Health Policy. Kathmandu: Ministry of Health and Population, 2014.

61. Sheppard P, Landry M. Lessons from the 2015 earthquake (s) in Nepal: implication for rehabilitation. Disabil Rehabil 2015;1-4. 